\title{
INCIDENTAL LEIOMYOMA IN MESH HERNIOPLASTY
}

\author{
C. Asha, Mahendra Shetty, Rohit, Ashok.
}
1. Assistant Professor, Department of General Surgery, ESICMC PERI MSR RNR, Bangalore.
2. Senior Resident, Department of General Surgery, ESICMC PERI MSR RNR, Bangalore.
3. Junior Resident, Department of General Surgery, ESICMC PERI MSR RNR, Bangalore.
4. Post graduate student, Department of General Surgery, ESICMC PERI MSR RNR, Bangalore.

\section{CORRESPONDING AUTHOR:}

C. Asha.

No. 35, SMRUTHI, 6th Main Road, Wer $2^{\mathrm{ND}}$ stage $2^{\mathrm{Nd}}$ phase, Banglore-560086

E-mail: asha clid@gmail.com

\begin{abstract}
Incidental finding of leiomyoma is rare finding and can mimic an inguinal hernia or both can occur at a time. Very small mass beside hernia sac identified during exploration of the inguinal canal. Inguinal hernia in females is less common compared to males, but more common than the femoral hernia. Beside the sac there may be other structures, which have been reported like lipoma of cord, lymph node. In our hospital we have come across this case, and would like to report. Confirmatory diagnosis is established by histopathology. Surgical excision is the curative treatment.
\end{abstract}

KEYWORDS: Leiomyoma, INCIDENTAL LEIOMYOMA, inguinal canal round ligament tumor, Inguinal leiomyoma.

INTRODUCTION: The round ligament extends from the uterus through the inguinal canal and terminates in the region of the mons pubis and labia majora. Embryologically, it is the female equivalent of the gubernaculum testis. This structure is responsible for the descent of the ovary from the posterior abdominal wall to the uterus. It is mainly composed of smooth muscle fibres, connective tissue, vessels, and nerves with a mesothelial coating. Leiomyoma originating from round ligament found during mesh hernia surgery is a rare condition hence reported

CASE REPORT: A 36-year-old woman presented to the surgical outpatient department of ESI PGIMSR BENGALURU, with painless swelling in the right inguinal region. It had been gradually increasing in size for the previous three months and was reducible. No other significant history noted. The round swelling measured $2 * 2 \mathrm{~cm}$ was reducible, and non-tender. The cough impulse was, however equivocal. A working diagnosis of right-sided inguinal hernia was made and, after routine blood tests and USG -inguinal hernia, no other abnormality detected, surgical exploration of the inguinal region was accomplished under spinal anaesthesia. Per-operatively, it was observed that she had indirect component hernia and a rounded swelling arising within the inguinal canal, was found attached to the round ligament. Mass was measuring about $1.5^{*} 1 \mathrm{~cm}$ oval swelling found beside the sac and mass separated and removed .MESH hernioplasty done for indirect component hernia. Mass sent for Histopathological examination. After 7 days histopathology revealed 
encapsulated firm to hard grey tissue with well-defined spindle cell lesions arranged in interlacing fascicles. The mass was composed of bland cells with cigar-shaped nuclei and eosinophilic cytoplasm consistent with leiomyoma without mitotic figures, atypia, or necrosis.

DISCUSSION: Incidental finding of leiomyoma are rare and can mimic an inguinal hernia. Very small mass beside hernia sac identified during exploration of the inguinal canal usually diagnosis is established by histopathology. Surgical excision is the curative treatment. Tumours of the round ligament of the uterus are quite rare. The most commonly found tumours are leiomyomas, followed by endometriosis and mesothelial cysts. Approximately, one-half to two-thirds of leiomyomas occur in the extra-peritoneal portion of the round ligament and are more common on the right side for unknown reasons. The transformation of the myofibrous structure of the female genital tract to leiomyoma involves somatic mutations of normal smooth muscle and a complex interaction between sex steroids and local growth factors. Estrogen is the major promoter of the myoma growth; however, the role of progesterone is still unclear, as both receptors have been found in the round ligament. The differentiation between benign and malignant tumors can be difficult as the major criteria for malignancy are mitotic figures, nuclear atypia, and necrosis. In $50 \%$ of the reported cases, the lesions are associated with uterine leiomyomas. Mass lesions that involve the extra-peritoneal portion of the round ligament as it passes through the inguinal canal can mimic an incarcerated inguinal hernia or inguinal adenopathy. In our case, the mass presented like an inguinal hernia. Pre-operative imaging techniques such as computed tomography (CT) scans can be helpful in diagnosing the condition, but it is not usually employed before surgical exploration. Leiomyoma presents as a circumscribed, heterogeneous, dense mass in CT images. It may contain calcifications that may be mottled, whorled, streaked, and curvilinear. Surgical exploration and intervention is adequate treatment as it would distinguish and treat both leiomyoma and inguinal hernia.

\section{REFERENCES:}

1. Sultan Qaboos Univ Med J. 2012 August; 12(3): 357-359. Published online 2012 July 15.

2. Text book of gynecology -Shaws 2012 , page 18,312

3. Schwartz textbook of surgery- chapter 36 inguinal hernia 2007

4. Fletcher CD, Tsang WY, Fischer $\mathrm{C}$ et al

5. David MW, Stanley RM. Leiomyoma of extra-peritoneal round ligament: CT demonstration. Clinical Imaging. 1999; 23:375-6

6. Williams PL, Bannister LH, Berry MM, Collins P, Stain M, Duse JE, et al., editors. Grey's Anatomy

7. Juan Rosai textbook of surgical pathology

8. Honore $\mathrm{H}$, Manickavel V, striated muscle heteroplasia in the uterine round ligament Arch pathol lab med 1991 115:223-225

9. Nuovo MA, Nuovo GJ Smith D Lewis SH benign mesenchyme of round ligament. A report of cases with immuno histo chemistry. Am J path 1990 93: 421-424 Bakotic B W Cabello Inch Hausti B, Willis I H, Suster S. Clear cell epitheloid leiomyoma of round ligament 


\section{CASE REPORT}

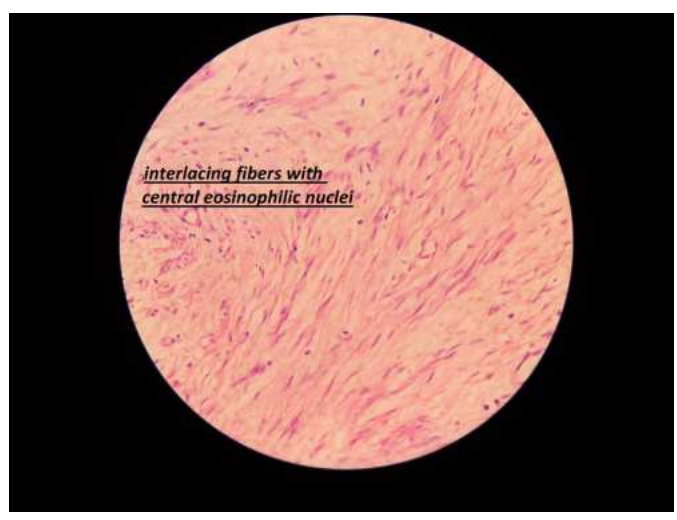

HISTOPATHOLOGY

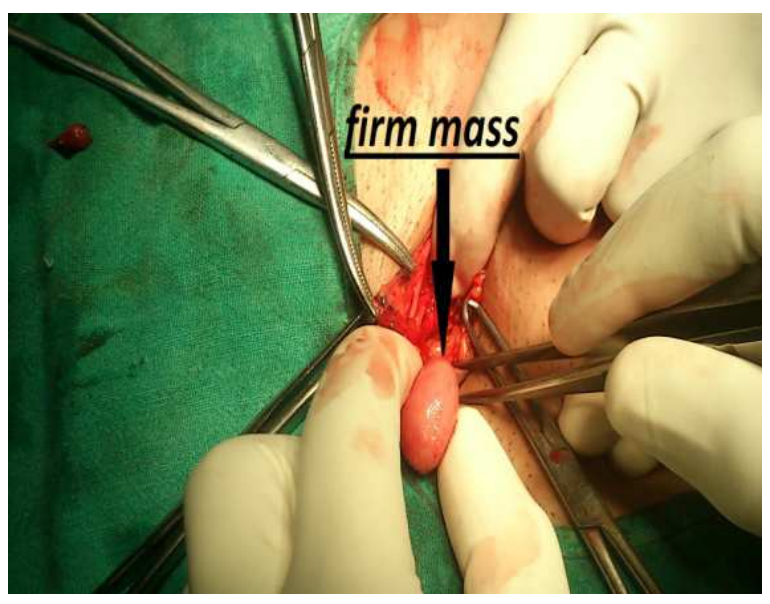

OPERATIVE FINDINGS

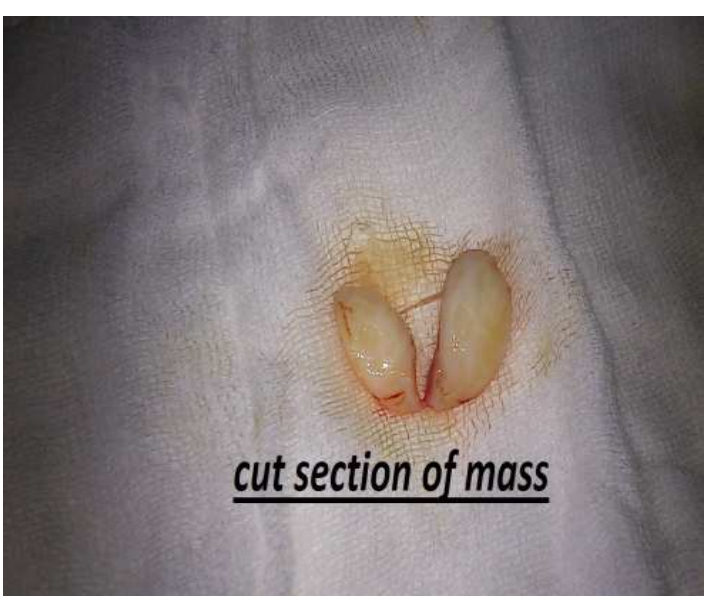

CUT SECTION OF MASS 